\title{
Structural, Optical, and Humidity Sensing Performance of Pb-Doped Zno Nanostructure Prepared by Sol-Gel Immersion Method
}

\author{
A.S. Ismail ${ }^{1}$, M.H. Mamat ${ }^{1,2}$, M.M. Yusoff ${ }^{1}$, M.F. Malek ${ }^{1,2}$, A.S. Zoolfakar ${ }^{1}$, R. Mohamed ${ }^{1}$, N.D. Md. Sin ${ }^{1}$, \\ W.R.W. Ahmad ${ }^{1}$, A.B. Suriani ${ }^{3}$, M.K. Ahmad ${ }^{4}$, I.B. Shameem Banu ${ }^{5}$, and M. Rusop ${ }^{1,2}$ \\ ${ }^{1}$ NANO-ElecTronic Centre (NET), Faculty of Electrical Engineering, Universiti Teknologi MARA (UiTM), \\ 40450, Shah Alam, Selangor, Malaysia,mhmamat@ salam.uitm.edu.my, \\ ${ }^{2}$ NANO-SciTech Centre, Institute of Science, Universiti Teknologi MARA, 40450, Shah Alam, Selangor, \\ Malaysia \\ ${ }^{3}$ Faculty of Science and Mathematics, Universiti Pendidikan Sultan Idris, Tanjung Malim, Perak 35900, Malaysia. \\ ${ }^{4}$ Microelectronic and Nanotechnology - Shamsuddin Research Centre (MiNT-SRC), Faculty of Electrical and \\ Electronic Engineering, Universiti Tun Hussein Onn Malaysia (UTHM), 86400 Batu Pahat, Johor, Malaysia \\ ${ }^{5}$ Department of Physics, B.S. Abdur Rahman Crescent Institute of Science \& Technology, Vandalur, \\ Chennai 600 048, India..mhmamat@salam.uitm.edu.my
}

\begin{abstract}
Lead $(\mathrm{Pb})$-doped zinc oxide $(\mathrm{ZnO})$ nanostructured film was prepared using sol-gel immersion method. The surface morphology of the $\mathrm{ZnO}$ films displayed a significant change in structure after doped with $\mathrm{Pb}$. The diameter of the nanostructures was increased from $50 \mathrm{~nm}$ to $80 \mathrm{~nm}$ after doped. Besides, the crystallinity of the film was improved after doped with $\mathrm{Pb}$, as well as the crystallite size of the $\mathrm{Pb}$-doped $\mathrm{ZnO}$ film. The $\mathrm{Pb}$-doped $\mathrm{ZnO}$ film showed excellent transmittance properties with average transmittance of $83 \%$. Pb-doped sample displayed better absorbance than that of undoped $\mathrm{ZnO}$ at $\mathrm{UV}$ region and also have high optical band gap energy of $3.27 \mathrm{eV}$. In addition, $\mathrm{Pb}$-doped $\mathrm{ZnO}$ film exhibited a stable response to humidity change with a sensitivity of 1.21 .
\end{abstract}

Key words : $\mathrm{ZnO}$ nanostructure, $\mathrm{Pb}$-doped, immersion, humidity sensor.

\section{INTRODUCTION}

Nowadays, zinc oxide $(\mathrm{ZnO})$ has been widely studied for various kinds of applications due to its characteristics such as non-toxic, wide band gap of $3.37 \mathrm{eV}$ and exciton binding energy of $60 \mathrm{meV}[1,2]$. Fabrication of $\mathrm{ZnO}$ in nanostructure scale is considerably importance due to high surface-to-volume ratio, small size, and better device performance [3, 4]. $\mathrm{ZnO}$ nanostructures can be synthesized through many kinds of preparation methods such as immersion, chemical vapor deposition, electron beam evaporation, and electrochemical-deposition methods [5-7]. Between the processes, immersion is one of the most commonly used. The preparation of $\mathrm{ZnO}$ nanorod arrays through a simple sol-gel method such as immersion usually produce device with high resistivity [8]. The adjustment on conductivity of the $\mathrm{ZnO}$ nanorods is crucial to improve their capability as a device for example through doping process with different kind of metal such as aluminium (Al), ferum $(\mathrm{Fe})$, magnesium $(\mathrm{Mg})$, and tin $(\mathrm{Sn})[9,10]$. In this research, effect of lead $(\mathrm{Pb})$ doping on the structural and optical properties of $\mathrm{ZnO}$ is discussed, together with their performance in humidity sensing. Although, $\mathrm{ZnO}$ nanorod properties were widely discussed in the literatures, effects of $\mathrm{Pb}$ doping into $\mathrm{ZnO}$ were rarely discussed in details especially for humidity sensing performance. Therefore, it is worth to investigate this topic to understand $\mathrm{Pb}$-doped $\mathrm{ZnO}$ behaviour in term of their structural, optical, and humidity sensing performance.

\section{EXPERIMENTAL PROCEDURES}

The development of the $\mathrm{ZnO}$ nanostructures film was built up by means of the sol-gel submersion technique onto Al-doped $\mathrm{ZnO}$ covered glass substrate. The detail arrangement has been accounted for somewhere else [11]. The $\mathrm{ZnO}$ seed layer arrangement was readied utilizing zinc acetic acid derivation dry out, aluminum nitrate and monoethanolamine. The readied arrangement was saved onto a glass substrate utilizing a turn covering strategy. The answer for developing nanostructured $\mathrm{ZnO}$ was readied utilizing zinc nitrate hexahydrate as a forerunner, hexamethylenetetramine as the stabilizer, aluminum nitrate nonahydrate as the dopant, and deionized (DI) water as the dissolvable.

The solution was sonicated using ultrasonic water bath and then stirrer for 3 hours. Then the sample was immersed in water bath tank for 1 hour to grow the $\mathrm{Pb}$-doped $\mathrm{ZnO}$ nanostructures. After deposition, the film was dried and annealed at $500{ }^{\circ} \mathrm{C}$. Gold $(\mathrm{Au})$ was coated on the film as metal contact. The synthesis of $\mathrm{Pb}$-doped $\mathrm{ZnO}$ nanostructures is illustrated in Fig. 1. Field-emission scanning electron microscopy (FESEM, JEOL JSM-7600F), X-ray diffraction (XRD; PANalytical X'Pert PRO), and energy-dispersive 
X-ray spectroscopy (EDS, Oxford Instruments Inca X-Act) were used to analysed the structural properties and elemental analysis of the films. UV-Vis-NIR spectrophotometer (Cary 5000) were used to observe the transmittance and absorbance of the films. Humidty sensor measurement system (Keithley 2400) were used to study the humidity sensing performance of the films.

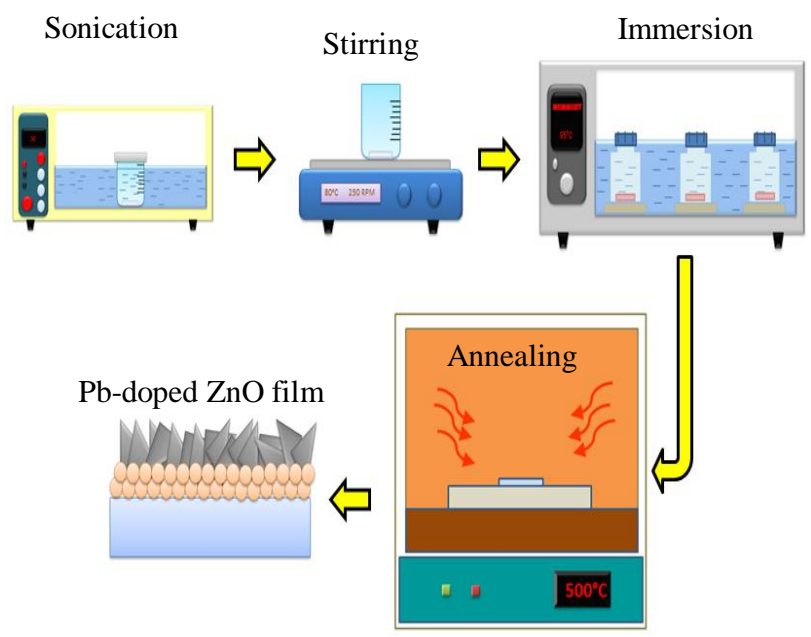

Figure 1: Preparation of $\mathrm{Pb}$-doped nanostructures

\section{EXPERIMENTAL RESULT}

\subsection{Structural Properties}

Fig. 2 shows the surface and cross-sectional images of undoped and $\mathrm{Pb}$-doped $\mathrm{ZnO}$ nanorod arrays. Undoped $\mathrm{ZnO}$ sample exhibits rice-like structure with average diameter about $50 \mathrm{~nm}$ and thickness about $200 \mathrm{~nm}$, whereas Pb-doped $\mathrm{ZnO}$ sample exhibits triangle-shape nanostructures with average diameters about $80 \mathrm{~nm}$ and thickness about $200 \mathrm{~nm}$. Both films are highly dense and has low pore channel in between the nanostructures. In addition, the increment of diameter after $\mathrm{Pb}$ doping may due to substitution of larger ionic radius of $\mathrm{Pb}^{2+}(1.19 \AA)$ replacing the $\mathrm{Zn}^{2+}(0.74 \AA)$ sites $[12,13]$. The elemental analysis in Fig. 2(e) confirms the availability of $\mathrm{Pb}$ atoms in the $\mathrm{ZnO}$ structure. According to the elemental analysis, the percentages of zinc $(\mathrm{Zn})$, oxygen $(\mathrm{O})$, and $\mathrm{Pb}$ are $54.81 \%, 44.90 \%$, and $0.29 \%$, respectively.

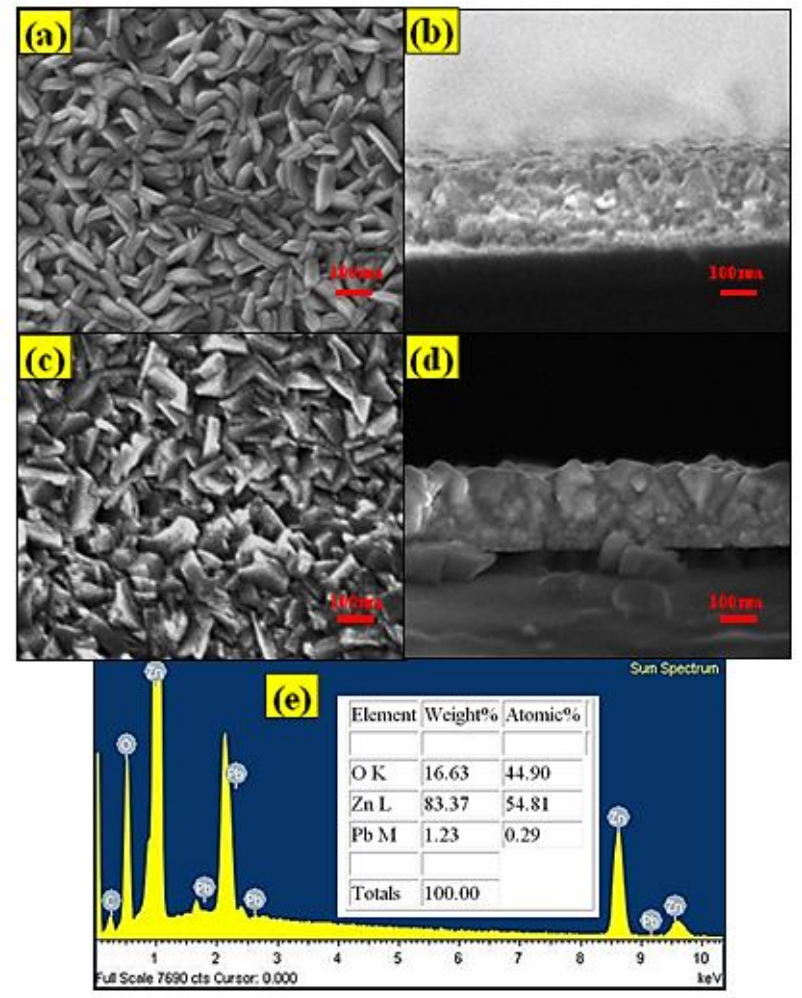

Figure 2: (a) Surface and (b) cross-sectional images of undoped $\mathrm{ZnO}$. (c) Surface and (d) cross-sectional images of $\mathrm{Pb}$-doped $\mathrm{ZnO}$. (e) Elemental analysis of $\mathrm{Pb}$-doped $\mathrm{ZnO}$

The structural properties of the films were further analyzed using XRD measurement as shown in Fig. 3. The XRD pattern showed that the films consist of $\mathrm{ZnO}$ hexagonal wurtzite structure with polycrystalline structure. The XRD peaks of both samples are correspond to (100), (002), (101), (102), and (110) of $\mathrm{ZnO}$ plane orientations with (101) plane displayed the highest intensity. No additional $\mathrm{PbO}$ peak can be observed which indicates that the film is purely $\mathrm{ZnO}$. Besides, we observed an enhancement of peak intensity especially for (002) plane which indicates that doping with $\mathrm{Pb}$ manage to improve the crystallinity of the $\mathrm{ZnO}$ film.

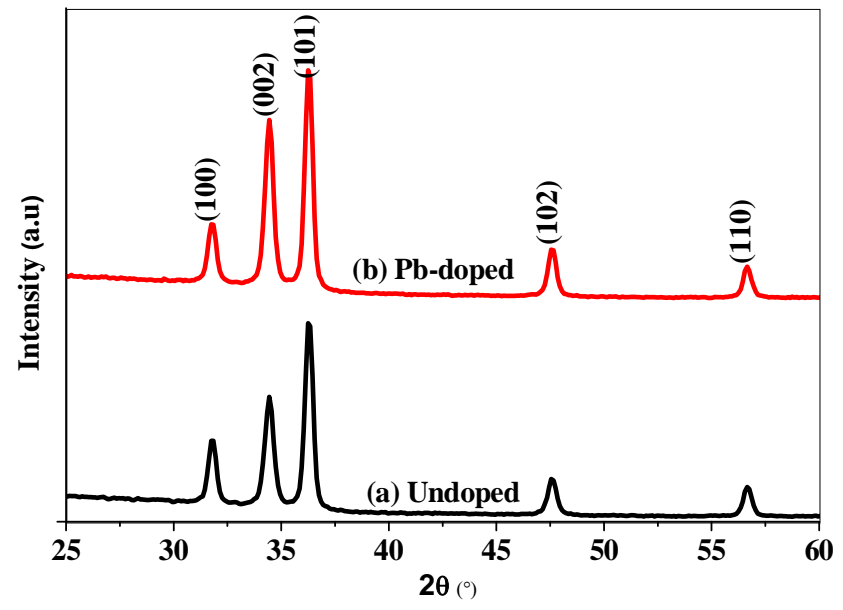

Figure 3: XRD pattern of (a) undoped and (b) $\mathrm{Pb}$-doped $\mathrm{ZnO}$ 
The average crystallite sizes were acquired from the given equation [14]:

$$
D=\frac{0.94 \lambda}{\beta \cos \theta}
$$

Here, $D$ is the crystallite size, $\lambda$ is the $\mathrm{X}$-rays wavelength used, $\beta$ is the line broadening at Full Width at Half Maximum intensity (FWHM), and $\theta$ is the Bragg diffraction angle. The values of $\beta$ and $\theta$ for undoped $\mathrm{ZnO}$ are recorded to be $0.4804^{\circ}$ and $17.22^{\circ}$, respectively, meanwhile for $\mathrm{Pb}$-doped $\mathrm{ZnO}$ are $0.4480^{\circ}$ and $17.22^{\circ}$, respectively. From the calculation, the average crystallite size of undoped and $\mathrm{Pb}$-doped $\mathrm{ZnO}$ is estimated to be 18.1 and $19.4 \mathrm{~nm}$, respectively. The increment of crystallite size may be provided by the substitution of larger ionic radius of $\mathrm{Pb}^{2+}$ into $\mathrm{ZnO}$ structure [12]. This finding is in agreement with the observation of FESEM images. On the basis of previous study, doping with $\mathrm{Pb}$ causes an increment of nanostructure sizes, leading to a film with lower stress [14]. As a result, the crystallinity of the film is improved.

\subsection{Optical Properties}

The optical properties of the films are shown in Fig. 4. Both samples exhibit good transmittance properties (Fig. 4(a)) in the visible region with average transmittance around $83 \%$. No significant changes to the transmittance properties after doped with $\mathrm{Pb}$. Meanwhile, the absorbance of Pb-doped sample is slightly higher than that of undoped $\mathrm{ZnO}$ at $\mathrm{UV}$ region (Fig. 4(b)). This increment of absorbance may be due to increment of optical scattering effect in the film provided by the enlargement of nanostructure size.
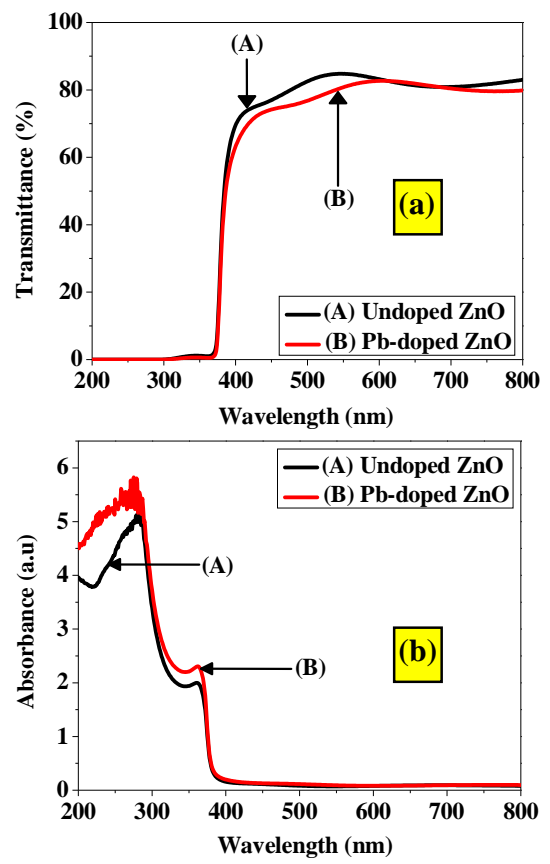

Figure 4: (a) Transmittance and (b) absorbance properties of undoped $\mathrm{ZnO}$ and $\mathrm{Pb}$-doped $\mathrm{ZnO}$

The optical band energy of the films was estimated using the following equation [15]-[16]:

$$
a h v=B\left(h v-E_{g}\right)^{\frac{1}{2}}
$$

where $\alpha, h v, E_{g}$, and $B$ are the absorption coefficient, photon energy, optical band gap energy, and energy-independent constant, respectively. The Tauc's plot is shown in Fig. 5. The estimated energy gap of the films is approximately $3.27 \mathrm{eV}$, which is close to the band gap energy of intrinsic $\mathrm{ZnO}$ (3.37 $\mathrm{eV})$. No changes to the energy gap can be observed after doping with $\mathrm{Pb}$. This may due to the similar thickness of both films and also no increment to the carrier concentration which leads to band gap shifting, in accordance to Burstein-Moss effect [8].

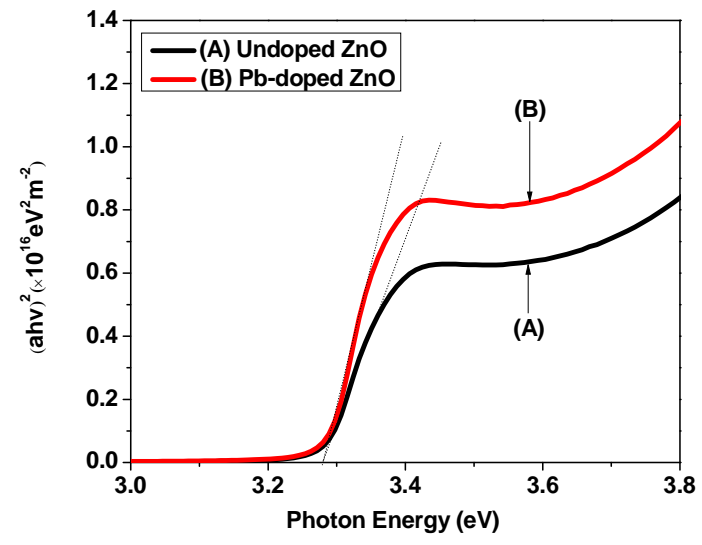

Figure 5: Tauc's plot for optical band gap energy estimations

\subsection{Humidity Sensor Performance}

The humidity sensor performance of undoped and $\mathrm{Pb}$-doped ZnO-based humidity sensors can be observed in Fig. 6. The undoped $\mathrm{ZnO}$-based humidity sensor displayed a gradual increase in current signal with slow response from $40 \%$ to $90 \%$ RH. However, Pb-doped ZnO-based humidity sensor produced high current signal change at low humidity level and then increased slowly when humidity level almost reaching $90 \%$ $\mathrm{RH}$. The sensitivities of the undoped- and $\mathrm{Pb}$-doped ZnO-based humidity sensors are estimated using the following equation [17]:

$$
S=\frac{R_{a}}{R_{r h}}
$$

Here, $S$ is the sensitivity, $R_{a}$ and $R_{r h}$ are the resistance at $40 \%$ and $90 \%$ RH, respectively. From the response curve, the sensitivities of undoped and $\mathrm{Pb}$-doped $\mathrm{ZnO}$-based humidity sensors are estimated to be 1.18 and 1.21 , respectively. Other than sensitivity, it is observed that the response curve of $\mathrm{Pb}$-doped sample possessed a smoother and stable current signal than that of undoped sample. The slight increment of sensitivity and stable adsorption/desorption processes may be due to better electron transport properties across the film of $\mathrm{Pb}$-doped $\mathrm{ZnO}$ film which possesses larger crystallite size. These results suggested that the performance and certain properties of $\mathrm{ZnO}$ nanostructures can be improved by doping with $\mathrm{Pb}$. 

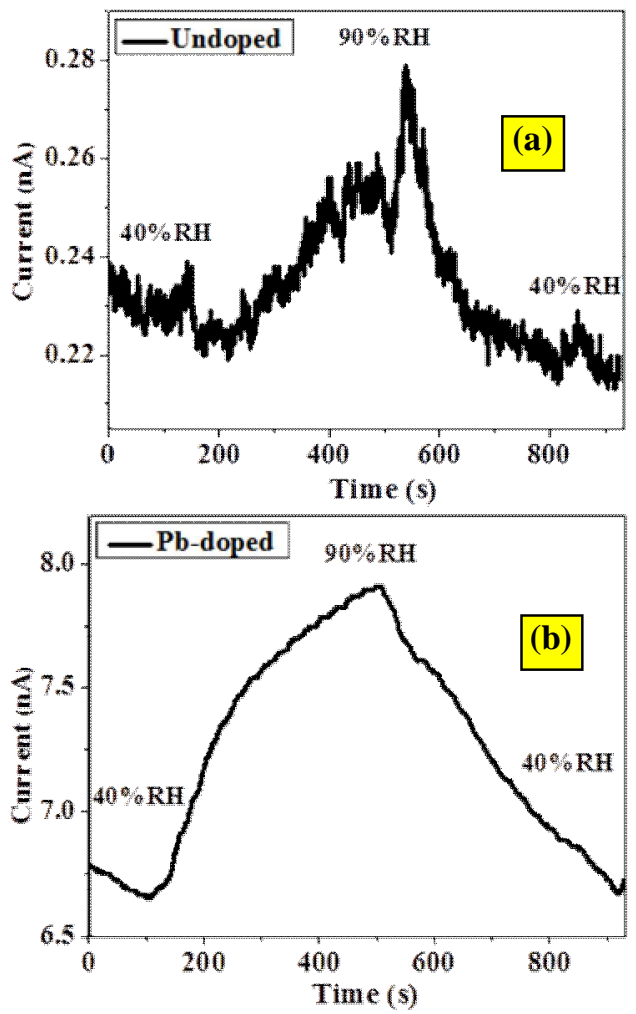

Figure 6: Humidity sensing response of (a) undoped and (b) $\mathrm{Pb}$-doped $\mathrm{ZnO}$

\section{CONCLUSION}

$\mathrm{Pb}$-doped $\mathrm{ZnO}$ nanostructures were successfully deposited using sol-gel immersion method. It is observed that $\mathrm{Pb}$ doping can alter the morphology of $\mathrm{ZnO}$ nanostructures and increasing the average diameter of the nanostructures. The diameter of the nanostructures was increased from 50 to $80 \mathrm{~nm}$ after doped. Besides, the crystallinity of the film improved after doped with $\mathrm{Pb}$. Furthermore, the crystallite size of the $\mathrm{Pb}$-doped film increased from 18.1 to $19.4 \mathrm{~nm}$. In addition, the optical properties of the films showed excellent transmittance properties of the $\mathrm{Pb}$-doped $\mathrm{ZnO}$ with average transmittance of $83 \%$. The $\mathrm{Pb}$-doped sample displayed better absorbance than that of undoped $\mathrm{ZnO}$ at UV region and high optical band gap energy of $3.27 \mathrm{eV}$. Pb-doped $\mathrm{ZnO}$ film showed a stable response to humidity change with a sensitivity of $1.21 \mathrm{~Pb}$ doping has slightly improved the performance of $\mathrm{ZnO}$-based humidity sensor in humidity detection. Thus, it is suggested that $\mathrm{Pb}$ is suitable to be used as dopant to enhance the $\mathrm{ZnO}$ properties.

\section{ACKNOWLEDGEMENT}

The author would like to thank Faculty of Electrical Engineering, UiTM for the financial support. This work was supported by the ASEAN-India Research \& Training Fellowship (IMRC/AISTDF/R\&D/P-1/2017). The authors also would like to thank the Institute of Research Management and Innovation (IRMI) of UiTM for their financial support of this research

\section{REFERENCES}

1. B. Sarma, B.K. Sarma, "Role of residual stress and texture of $\mathrm{ZnO}$ nanocrystals on electro-optical properties of $\mathrm{ZnO} / \mathrm{Ag} / \mathrm{ZnO}$ multilayer transparent conductors", Journal of Alloys and Compounds, 734, (2018), pp.210-219. https://doi.org/10.1016/j.jallcom.2017.11.028

2. E. Przezdziecka, J.M. Sajkowski, M. Stachowicz, A. Kozanecki, "Luminescence related to two-dimensional gas in ZnO/ZnMgO heterostructures", Thin Solid Films, 643, (2017), pp.31-35. https://doi.org/10.1016/j.tsf.2017.06.015

3. Y. Dou, F. Wu, C. Mao, L. Fang, S. Guo, M. Zhou, "Enhanced photovoltaic performance of $\mathrm{ZnO}$ nanorod-based dye-sensitized solar cells by using Ga doped ZnO seed layer", Journal of Alloys and Compounds, 633, (2015), pp.408-414. https://doi.org/10.1016/j.jallcom.2015.02.039

4. M.H. Mamat, M.F. Malek, N.N. Hafizah, M.N. Asiah, A.B. Suriani, A. Mohamed, N. Nafarizal, M.K. Ahmad, M. Rusop, "Effect of oxygen flow rate on the ultraviolet sensing properties of zinc oxide nanocolumn arrays grown by radio frequency magnetron sputtering', Ceramics International, 42, (2016), pp.4107-4119.

https://doi.org/10.1016/j.ceramint.2015.11.083

5. G. Nagaraju, Y.H. Ko, J.S. Yu, 'Effect of diameter and height of electrochemically-deposited $\mathrm{ZnO}$ nanorod arrays on the performance of piezoelectric nanogenerators", Materials Chemistry and Physics, 149-150, (2015), pp. 393-399.

https://doi.org/10.1016/j.matchemphys.2014.10.034

6. I.N. Reddy, C.V. Reddy, M. Sreedhar, M. Cho, J. Shim, V.R. Reddy, C.-J. Choi, D. Kim, 'Effect of seed layers (Al, Ti) on optical and morphology of Fe-doped ZnO thin film nanowires grown on Si substrate via electron beam evaporation", Materials Science in Semiconductor Processing, 71, (2017), pp.296-303. https://doi.org/10.1016/j.mssp.2017.08.015

7. K. Lovchinov, G. Marinov, M. Petrov, N. Tyutyundzhiev, T. Babeva, "Influence of $\mathbf{Z n C l 2}$ concentration on the structural and optical properties of electrochemically deposited nanostructured ZnO”, Applied Surface Science, 456, (2018), pp.69-74.

https://doi.org/10.1016/j.apsusc.2018.06.088

8. A.S. Ismail, M.H. Mamat, N.D. Md. Sin, M.F. Malek, A.S. Zoolfakar, A.B. Suriani, A. Mohamed, M.K. Ahmad, M. Rusop, "Fabrication of hierarchical Sn-doped ZnO nanorod arrays through sonicated sol-gel immersion for room temperature, resistive-type humidity sensor applications", Ceramics International, 42, (2016), pp.9785-9795. https://doi.org/10.1016/j.ceramint.2016.03.071

9. N. Chahmat, T. Souier, A. Mokri, M. Bououdina, M.S. Aida, M. Ghers, "Structure, microstructure and optical properties of Sn-doped ZnO thin films", Journal of Alloys and Compounds, 593, (2014), pp.148-153.

https://doi.org/10.1016/j.jallcom.2014.01.024 
10. S.A. Azzez, Z. Hassan, J.J. Hassan, M.S. Mukhlif, M.S. Mahdi, M. Bououdina, "Effect of temperature on hydrothermally grown high-quality single-crystals Mg-doped ZnO nanorods for light-emitting diode application", Journal of Luminescence, 192, (2017), pp.634-643.

https://doi.org/10.1016/j.jlumin.2017.07.050

11. M.H. Mamat, M.Z. Sahdan, Z. Khusaimi, A.Z. Ahmed, S. Abdullah, M. Rusop, "Influence of doping concentrations on the aluminum doped zinc oxide thin films properties for ultraviolet photoconductive sensor applications", Optical Materials, 32, (2010), pp.696-699.

https://doi.org/10.1016/j.optmat.2009.12.005

12. R. Yousefi, F. Jamali-Sheini, A. Sa'aedi, A.K. Zak, M. Cheraghizade, S. Pilban-Jahromi, N. Ming Huang, "Influence of lead concentration on morphology and optical properties of $\mathrm{Pb}$-doped $\mathrm{ZnO}$ nanowires", Ceramics International, 39, (2013), pp.9115-9119.

https://doi.org/10.1016/j.ceramint.2013.05.008

13. M. Yilmaz, Ş. Aydoğan, "The effect of Pb doping on the characteristic properties of spin coated $\mathrm{ZnO}$ thin films: Wrinkle structures", Materials Science in Semiconductor Processing, 40, (2015), pp.162-170. https://doi.org/10.1016/j.mssp.2015.06.064

14. M.F. Malek, M.H. Mamat, M.Z. Musa, T. Soga, S.A. Rahman, S.A.H. Alrokayan, H.A. Khan, M. Rusop, "Metamorphosis of strain/stress on optical band gap energy of ZAO thin films via manipulation of thermal annealing process", Journal of Luminescence, 160 , (2015), pp.165-175. https://doi.org/10.1016/j.jlumin.2014.12.003

15. M. Jlassi, I. Sta, M. Hajji, H. Ezzaouia, "Effect of nickel doping on physical properties of zinc oxide thin films prepared by the spray pyrolysis method", Applied Surface Science, 301, (2014), pp.216-224. https://doi.org/10.1016/j.apsusc.2014.02.045

16. R. Mohamed, M.H. Mamat, A.S. Ismail, M.F. Malek, A.S. Zoolfakar, Z. Khusaimi, A.B. Suriani, A. Mohamed, M.K. Ahmad, M. Rusop, "Hierarchically assembled tin-doped zinc oxide nanorods using low-temperature immersion route for low temperature ethanol sensing", Journal of Materials Science: Materials in Electronics, 28, (2017), pp.16292-16305. https://doi.org/10.1007/s10854-017-7535-9

17. A.S. Ismail, M.H. Mamat, M.M. Yusoff, M.F. Malek, A.S. Zoolfakar, R.A. Rani, A.B. Suriani, A. Mohamed, M.K. Ahmad, M. Rusop, 'Enhanced humidity sensing performance using Sn-Doped $\mathrm{ZnO}$ nanorod Array/SnO2 nanowire heteronetwork fabricated via two-step solution immersion", Materials Letters, 210, (2018), pp.258-262.

https://doi.org/10.1016/j.matlet.2017.09.040 